\title{
The Effectiveness of Different Concepts of Bracing in Adolescent Idiopathic Scoliosis (AIS): A Systematic Review and Meta-Analysis
}

\author{
Lorenzo Costa (D), Tom P. C. Schlosser (D), Hanad Jimale, Jelle F. Homans, Moyo C. Kruyt and René M. Castelein *D \\ Department of Orthopaedic Surgery, University Medical Center Utrecht, 3508 GA Utrecht, The Netherlands; \\ L.Costa-2@umcutrecht.nl (L.C.); T.P.C.Schlosser@umcutrecht.nl (T.P.C.S.); h.jimale@students.uu.nl (H.J.); \\ J.F.Homans-3@umcutrecht.nl (J.F.H.); M.C.Kruyt@umcutrecht.nl (M.C.K.) \\ * Correspondence: R.M.Castelein@umcutrecht.nl; Tel.: +31-(88)-755-4578; Fax: +31-(30)-251-06-38
}

check for updates

Citation: Costa, L.; Schlosser, T.P.C.; Jimale, H.; Homans, J.F.; Kruyt, M.C.; Castelein, R.M. The Effectiveness of Different Concepts of Bracing in Adolescent Idiopathic Scoliosis (AIS): A Systematic Review and MetaAnalysis. J. Clin. Med. 2021, 10, 2145. https://doi.org/10.3390/jcm10102145

Academic Editor: Theodoros

B. Grivas

Received: 7 May 2021

Accepted: 12 May 2021

Published: 15 May 2021

Publisher's Note: MDPI stays neutral with regard to jurisdictional claims in published maps and institutional affiliations.

Copyright: (c) 2021 by the authors. Licensee MDPI, Basel, Switzerland. This article is an open access article distributed under the terms and conditions of the Creative Commons Attribution (CC BY) license (https:// creativecommons.org/licenses/by/ $4.0 /)$.
Abstract: Brace treatment is the most common noninvasive treatment in adolescent idiopathic scoliosis (AIS); however it is currently not fully known whether there is a difference in effectiveness between brace types/concepts. All studies on brace treatment for AIS were searched for in PubMed and EMBASE up to January 2021. Articles that did not report on maturity of the study population were excluded. Critical appraisal was performed using the Methodological Index for Non-Randomized Studies tool (MINORS). Brace concepts were distinguished in prescribed wearing time and rigidity of the brace: full-time, part-time, and night-time, rigid braces and soft braces. In the meta-analysis, success was defined as $\leq 5^{\circ}$ curve progression during follow-up. Of the 33 selected studies, 11 papers showed high risk of bias. The rigid full-time brace had on average a success rate of $73.2 \%$ (95\% CI $61-86 \%)$, night-time of $78.7 \%(72-85 \%)$, soft braces of $62.4 \%(55-70 \%)$, observation only of $50 \%$ (44-56\%). There was insufficient evidence on part-time wear for the meta-analysis. The majority of brace studies have significant risk of bias. No significant difference in outcome between the night-time or full-time concepts could be identified. Soft braces have a lower success rate compared to rigid braces. Bracing for scoliosis in Risser 0-2 and 0-3 stage of maturation appeared most effective.

Keywords: systematic review; meta-analysis; adolescent idiopathic scoliosis; brace therapy; brace concepts; rigid brace; night time brace

\section{Introduction}

Idiopathic scoliosis is a deviation from normal growth of the spine and trunk, with a prevalence of $2-4 \%$ in the general population [1]. Its management depends on the magnitude of the spinal curvature. Observation is indicated for mild curves and brace treatment is normally recommended in curves between $20^{\circ}$ and $45^{\circ}[2,3]$. The application of many different brace concepts (distinguished in prescribed wearing time and rigidity of the brace: full-time, part-time, and night-time, rigid braces and soft braces) have been described in the literature. They all apply different degrees of external corrective forces to the trunk to correct the complex 3-D spinal deformity. Full time braces usually aim at in-brace correction of the curve to at least $50 \%$ of the original magnitude; nighttime braces are a bit more ambitious and aim to correct about $70 \%$ or an even higher percentage of the curve while the brace is worn $[4,5]$.

The "Bracing in Adolescent Idiopathic Scoliosis Trial" (BRAIST) has provided highquality evidence for the application of full-time rigid brace treatment in AIS patients with curves $20-40^{\circ}$ before skeletal maturity [6]. For other concepts of bracing, most studies are retrospective and not controlled [7]. Despite the efforts of societies like SRS and SOSORT, high-quality evidence for the effectiveness of other concepts of bracing is still lacking. Furthermore, due to the development of multiple braces and non-standardized 
criteria, it is difficult to compare the results. Nevertheless, many studies provide insight in effectiveness $[6,8,9]$.

The aim of this systematic review and meta-analysis is to evaluate the literature on the effectiveness of different concepts of brace treatment, in terms of effect on spinal curve magnitude. The questions are:

1. What is the most effective brace concept?

2. What is the most effective brace type (Boston brace, Providence brace, etc.)?

3. What is the effect of skeletal maturity on the effectiveness of different concepts of brace treatment?

Even though Randomized Control Trials (RCTs) are considered to be more reliable than observational studies when evaluating treatment effectiveness, RCTs are extremely demanding for these types of questions and often fail [10]. Meta-epidemiological research has shown that for non-pharmaceutical purposes, alternative study designs are not consistently more biased and should not be discarded. Therefore, we also included observational studies [11-14]. To allow assessment of this wide array of studies, tools are available to appraise study quality for non-comparative studies [15].

Lastly, many definitions of success rate such as $\leq 5^{\circ}, \leq 10^{\circ}$, or avoidance of surgery are used in scoliosis brace studies. As this heterogeneity would have affected the outcome of this review, the authors agreed to use, at least for the meta-analysis, the most used definition: $\leq 5^{\circ}$ of curve progression as successful treatment.

\section{Materials and Methods}

\subsection{Protocol}

This systematic review was performed according to the PRISMA statement and is registered at PROSPERO with the ID CRD42020157636 [16].

\subsection{Search Methods and Study Selections}

A systematic search was undertaken to identify all studies reporting on bracing in AIS in PubMed and EMBASE till January 2021 (see Table 1). Inclusion criteria were shown in Table 2.

All studies that reported on spinal deformities other than AIS or with mixed-age population that did not report the outcomes for AIS separately were excluded. Since skeletal maturity is considered a significant parameter, if not stated, the studies were excluded from further analyses. Reviews, cross-sectional studies, and case series with less than 10 patients were also excluded (see Table 2). Title/abstract and full-text screening was done by two independent investigators. To ensure literature saturation, reference lists of included studies or relevant reviews identified through the search were reviewed.

Table 1. Strategy of the search in PubMed and Embase. There was no language restriction. Duplicates were removed in Rayyan [17].

(((scoliosis [MeSH Terms] OR scolio * [Title/Abstract] OR spinal curvature [Title/Abstract] OR AIS [Title/Abstract]))) AND ((((brace [MeSH Terms] OR brace [Title/Abstract] OR bracing [Title/Abstract]))) AND ((time [Title/Abstract] OR parttime [Title/Abstract] OR nighttime [Title/Abstract] OR compliance [MeSH

PubMed Terms] OR compliance [Title/Abstract] OR compliant [Title/Abstract] OR effect [Title/Abstract] OR treatment * [Title/Abstract] OR result [Title/Abstract] OR results [Title/Abstract] OR therap [Title/Abstract] OR mental disorder [Title/Abstract] OR hypersensitive [Title/Abstract] OR peer problem [Title/Abstract] OR depress [Title/Abstract]) OR psychologic [Title/Abstract] OR quality of life [Title/Abstract] OR quality of life [MeSH] OR life quality [Title/Abstract])))).

('scoliosis': exp OR 'scolio *': ti, ab, kw OR 'spinal curvature *': ti, ab, kw OR 'AIS': ti, ab, kw) AND ('brace': exp OR 'brace *': ti, ab, kw OR 'braci *': ti, ab, kw) AND ('time': ti, ab, kw OR 'parttime': ti, ab, kw OR 'nighttime': ti, Medscape ab, kw OR 'compliance': exp OR 'compliance': ti, ab, kw OR 'compliant': ti, ab, kw OR 'effect ${ }^{* \prime}$ : ti, ab, kw OR 'treatment ${ }^{* \prime}$ : ti, ab, kw OR 'result': ti, ab, kw OR 'results': ti, ab, kw OR 'therap ${ }^{* \prime}: \mathrm{ti}, \mathrm{ab}, \mathrm{kw}$ OR 'mental disorder

*': ti, ab, kw OR 'hypersensitiv *': ti, ab, kw OR 'peer problem *': ti, ab, kw OR 'depress *': ti, ab, kw OR 'psychologic *': ti, ab, kw OR 'quality of life': ti, ab, kw OR 'quality of life': exp OR 'life quality': ti, ab, kw) 
Table 2. Details regarding inclusion criteria.

\begin{tabular}{ccc}
\hline $\mathbf{1}$ & Design & $\begin{array}{c}\text { Longitudinal studies with at least one-year follow-up from } \\
\text { brace initiation }\end{array}$ \\
\hline $\mathbf{2}$ & Population & Patients with adolescent idiopathic scoliosis \\
\hline $\mathbf{3}$ & Intervention & $\begin{array}{r}\text { Specification of the concept(s) of brace (prescribed wearing } \\
\text { time(s) and brace type(s)) used }\end{array}$ \\
\hline $\mathbf{4}$ & Outcome & $\begin{array}{l}\text { A definition of success rate (all definitions of success rate } \\
\text { were accepted in the qualitative synthesis in this review) }\end{array}$ \\
\hline
\end{tabular}

\subsection{Appraisal}

Two authors independently assessed the quality and risk of bias of each included study using the validated Methodological Index for Non-Randomized Studies (MINORs) (see Table 3) [15]. For any disagreement, consensus was reached by discussion.

Table 3. The MINOR tool [15]. Items 1-8 are for both comparative and non-comparative studies. Items 9-12 are only for comparative studies. The items are scored 0 (not reported), 1 (reported but inadequate), or 2 (reported and adequate), the global ideal score being 16 for non-comparative studies and 24 for comparative studies. For comparative studies: $<12$ high risk of bias, $12-16$ medium risk of bias, $>16$ low risk of bias. For non-comparative studies: $<7$ high risk of bias, $7-11$ medium risk of bias, $>11$ low risk of bias.

\begin{tabular}{|c|c|c|}
\hline 1 & A clearly stated aim & The question address should be precise and relevant. \\
\hline 2 & $\begin{array}{l}\text { Inclusions of } \\
\text { consecutive patients }\end{array}$ & $\begin{array}{l}\text { All patients potentially fit for inclusion had been included in } \\
\text { the study. }\end{array}$ \\
\hline 3 & Prospective collection data & $\begin{array}{l}\text { Data were collected according to a protocol established before the } \\
\text { beginning of the study. }\end{array}$ \\
\hline 4 & $\begin{array}{l}\text { Endpoints appropriate to the } \\
\text { aim of the study }\end{array}$ & $\begin{array}{l}\text { Unambiguous explanation of the criteria used to evaluate the } \\
\text { main outcome. }\end{array}$ \\
\hline 5 & $\begin{array}{l}\text { Unbiased assessment of the } \\
\text { study endpoint }\end{array}$ & $\begin{array}{l}\text { Blind evaluation of objective end-points and double } \\
\text { blind-evaluation of subjective endpoints. Other explanation of } \\
\text { the reasons for not blinding. }\end{array}$ \\
\hline 6 & $\begin{array}{l}\text { Follow-up period appropriate } \\
\text { to the aim of the study }\end{array}$ & $\begin{array}{l}\text { The follow-up should be should be sufficiently long to allow the } \\
\text { assessment of the main end-points. }\end{array}$ \\
\hline 7 & Loss to follow-up less than $5 \%$ & $\begin{array}{l}\text { All patients should be included in the follow-up. Otherwise, the } \\
\text { proportion lost should not exceed the proportion experiencing } \\
\text { the major end-points. }\end{array}$ \\
\hline 8 & $\begin{array}{l}\text { Prospective calculation of the } \\
\text { study size }\end{array}$ & $\begin{array}{l}\text { Information of the size of detectable difference of interest with a } \\
\text { calculation of } 95 \% \text { confidence interval. }\end{array}$ \\
\hline 9 & An adequate control group & $\begin{array}{l}\text { Having a gold standard diagnostic test or therapeutic } \\
\text { intervention recognized as the optimal intervention according to } \\
\text { the available published data. }\end{array}$ \\
\hline 10 & Contemporary groups & $\begin{array}{l}\text { Control and studied group should be managed during the same } \\
\text { time period. }\end{array}$ \\
\hline 11 & Baseline equivalence of groups & $\begin{array}{l}\text { The groups should be similar regarding criteria and studied } \\
\text { end-point. }\end{array}$ \\
\hline 12 & Adequate statistical analysis & $\begin{array}{l}\text { Whether the statistics were in accordance with the type of study } \\
\text { with calculation of confidence interval or relative risk. }\end{array}$ \\
\hline
\end{tabular}

\subsection{Synthesis}

Brace concepts and brace types, prescribed wearing time, actual wearing time (if reported), rigidity of the brace, maturity parameters, age, sex, curve magnitude, and outcomes (effect on curve magnitude and prevention of the need of surgery) were systematically collected and compared between the different brace concepts/types. Since heterogeneity in quality, methodology, and outcomes of the different studies was expected, a best-evidence-synthesis was performed in the form of a systematic qualitative 
synthesis [18]. The qualitative synthesis describes the outcomes of non-comparative and comparative studies on the different brace concepts/types. Because the majority of the studies report on success rates defined as $\leq 5^{\circ}$ progression during study follow-up, success rates are reported according to this definition (otherwise indicated in the text). Follow-up is intended after at least 1 year of follow-up and/or after termination of brace treatment.

The meta-analysis was performed on the outcomes of studies with low risk-of-bias that reported on the effectiveness of different brace concepts or braces as defined as $\leq 5^{\circ}$ coronal curve angle progression during study follow-up. In addition, the same was made with $\leq 50^{\circ}$ of Cobb angle progression. OpenMeta Analyst was used to execute the analysis [19]. Mean success rate and $95 \%$ confidence intervals (95\% CI) were calculated and compared between the concepts. Only the BRAIST study included data on untreated patients. Due to lack of other studies with control groups, two studies not included in this review on the natural history of AIS were used for calculation of the success rate of observation only $(n=267)[20,21]$.

The effect of skeletal maturity on the success of the brace treatment was analyzed using the same criteria as the meta-analysis. Outcomes were compared between studies with different skeletal maturity at inclusion: Risser sign $0-1,0-2,0-3$, and $0-4$.

\section{Results}

\subsection{Search}

The search yielded a total of 2609 papers. The PRISMA flowchart and reason for exclusion are shown in Figure 1. After title/abstract screening, 224 articles were selected for full-text reading. Reference tracking yielded no additional articles. After exclusions, a total of 33 articles were included in this study.

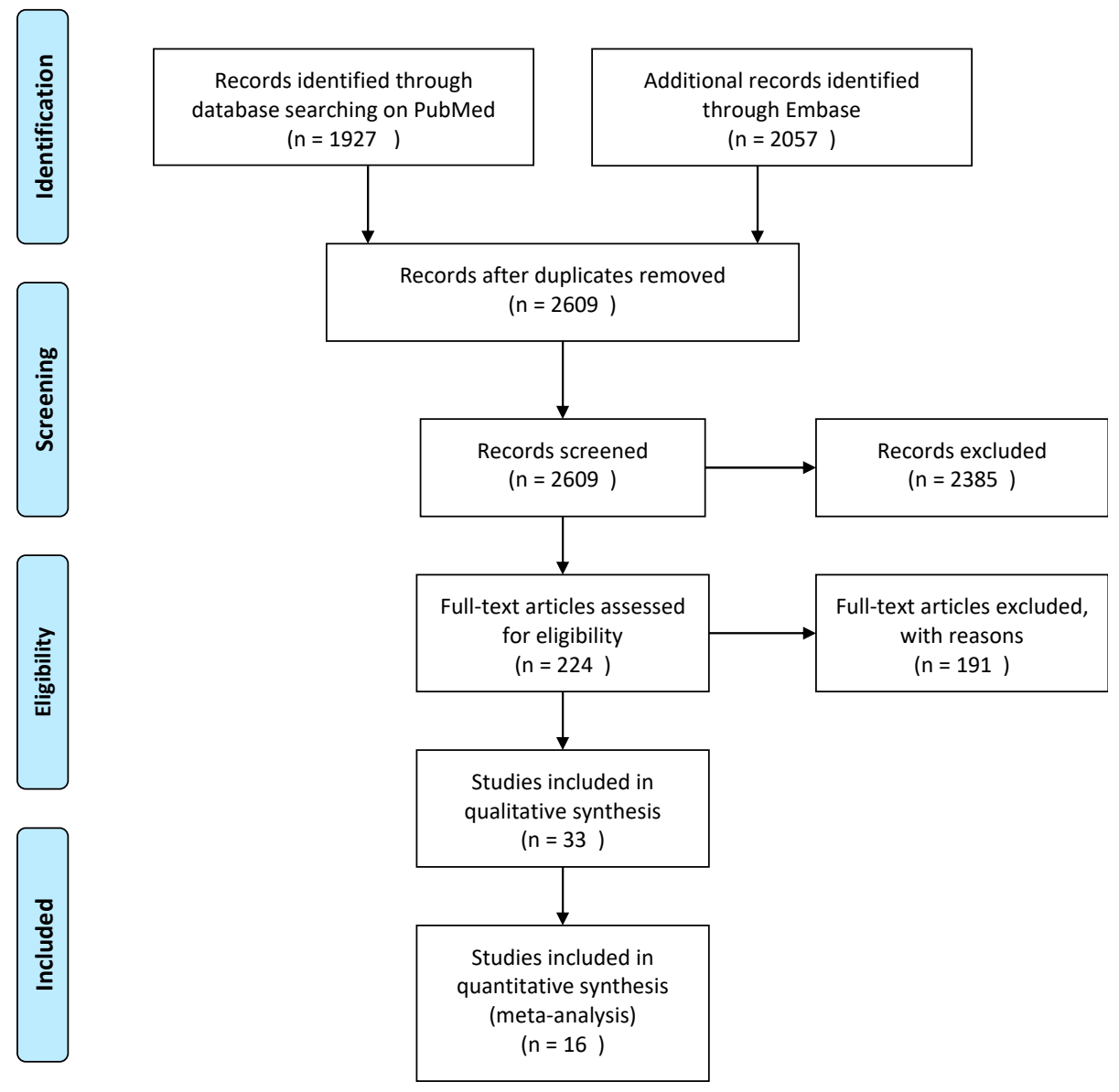

Figure 1. Flowchart of literature search. 


\subsection{Study Characteristic}

In total, seven types of rigid, full-time braces; two types of rigid, part-time braces; two types of rigid, night-time braces; and one soft, full-time brace were described in the 33 studies (see Table 4 ).

Table 4. Overview of the different braces included in this systematic review.

\begin{tabular}{clc}
\hline Brace Type & Rigidity & Prescribed Wearing Time \\
\hline Boston [22-24] & Rigid brace & Full-time/part-time \\
Cheneau brace [25-28] & Rigid brace & Full-time/part-time \\
PASB (Progressive Action Short Brace) [29] & Rigid brace & Full-time \\
Lyon brace [30] & Rigid brace & Full-time \\
Gensingen Brace [31] & Rigid brace & Full-time \\
OMC (Osaka Medical College) brace [32] & Rigid brace & Full-time \\
Pressure-adjustable orthosis [33] & Rigid brace & Full-time \\
Charleston brace [34,35] & Rigid brace & Night-time \\
Providence brace [5,36-39] & Rigid brace & Night-time \\
SpineCor [40,41] & Soft brace & Full-time \\
\hline
\end{tabular}

The study population varied between 23 and 843 patients per study. To one of the RCTs, patient preference cohorts were added during the inclusion period [6]. Seven studies (21\%) recruited patients in Asia, seven (21\%) in North-America and nineteen (58\%) in Europe. All studies reported on prescribed wearing time and three studies reported on actual wearing time as assessed by a thermomonitor or by the orthoptist $[6,42,43]$. Concerning the Cobb angle, the inclusion criteria of the non-comparative studies were:

1. Rigid full-time braces (15 studies): $30 \% 20-40^{\circ}, 30 \% 25-40^{\circ}, 8 \% 25-45^{\circ}, 8 \% \geq 40^{\circ}$, $8 \%>25^{\circ}, 8 \% 0-45^{\circ}$.

2. Night-time braces (8 studies): $63 \% 25-40^{\circ}, 13 \% 20-45^{\circ}, 13 \% 25-49^{\circ}, 13 \%<25^{\circ}$.

3. Soft full-time braces ( 2 studies): $50 \% 25-40^{\circ}, 50 \% 15-40^{\circ}$.

For the comparative studies (8 studies): $50 \% 25-40^{\circ}, 26 \%>25^{\circ}, 13 \% 20-30^{\circ}, 13 \%$ $15-30^{\circ}$ for soft braces and $>30^{\circ}$ for rigid full-time braces.

At the inclusion, most of the studies reported a magnitude between $25-40^{\circ}$ for the Cobb angle. Two papers presented a mean Cobb angle above $40^{\circ}$ and one paper below $20^{\circ}$.

In total, $69 \%$ of the studies included thoracic, thoracolumbar, and lumbar curves; $25 \%$ included thoracolumbar curves; and $6 \%$ double major curves.

The radiographic skeletal maturity at initiation of the treatment was reported in all papers. Of the studies, 32 used the Risser sign and one study only used menarche as a proxy for maturity [39]. Of those, $3 \%$ used the Risser sign between $0-1$ (as subgroup), $70 \%$ between $0-2,18 \%$ between $0-3,3 \%$ between $0-4,3 \%$ used Risser $0-1$ and Tanner between 2-3, and 3\% used Risser 0-2 and menarche period as well (pre-menarche or 1 year post-menarche) (see Tables 5 and 6).

\subsection{Study Quality}

The critical appraisal results are shown in Tables 5 and 6 . The mean quality score of the 3 RCTs was 14.5 (out of 24); of the 8 comparative cohort studies 10.7 (out of 24); and of the 24 non-comparative cohort studies, 8.1 (out of 16). Twelve studies had low quality and high risk-of-bias and six did not report on success defined as $\leq 5^{\circ}$ progression. A total of sixteen papers were included in the meta-analysis. There was insufficient evidence available to include the part-time, rigid brace concept in the meta-analysis. Quality of the two studies added for the control group was $7 / 16$ and 15/24 [20,21]. 
Table 5. Overview of the non-comparative studies. The studies lightened in bold are the ones included in the meta-analysis.

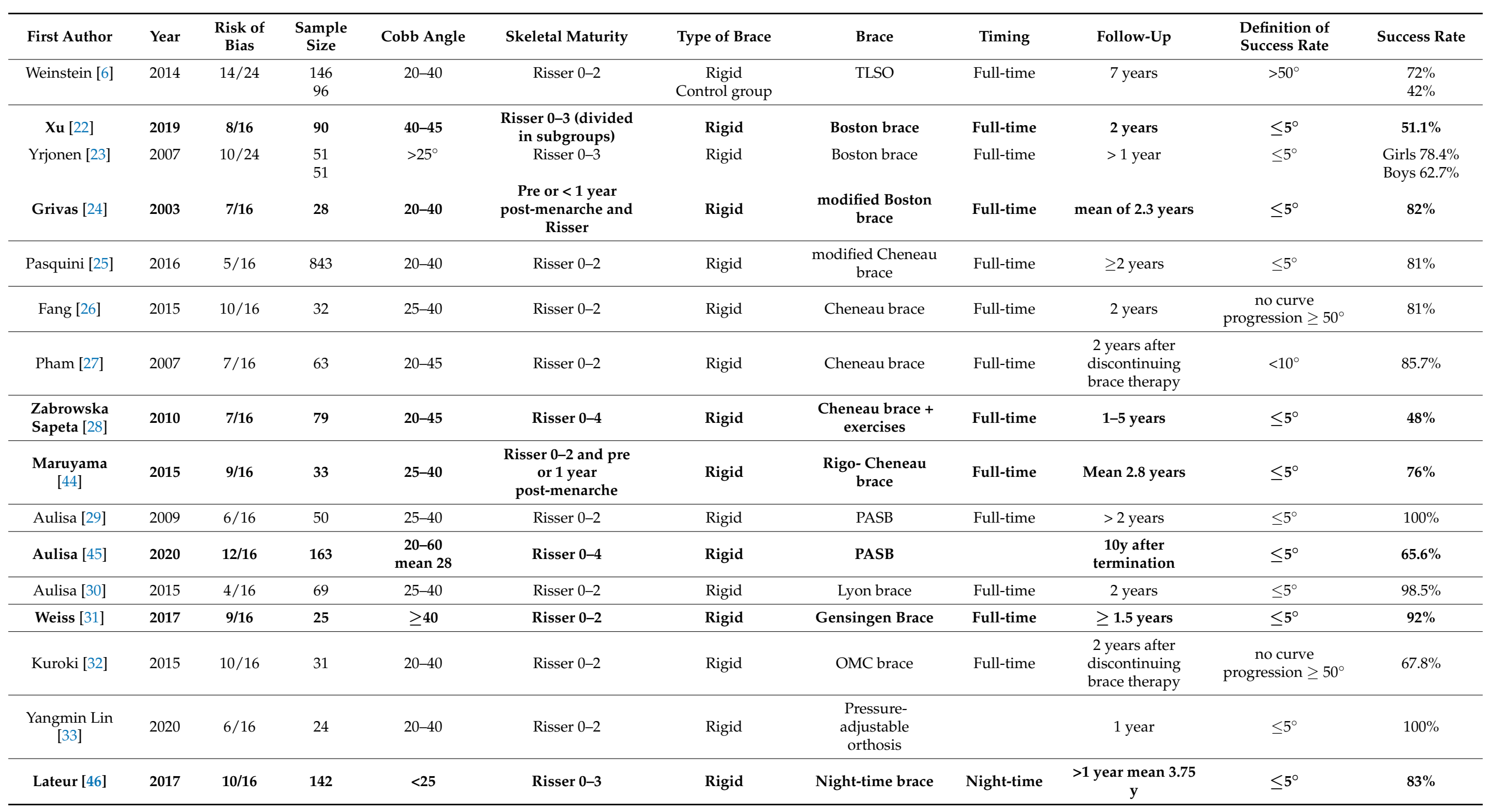


Table 5. Cont.

\begin{tabular}{|c|c|c|c|c|c|c|c|c|c|c|c|}
\hline First Author & Year & $\begin{array}{c}\text { Risk of } \\
\text { Bias }\end{array}$ & $\begin{array}{l}\text { Sample } \\
\text { Size }\end{array}$ & Cobb Angle & Skeletal Maturity & Type of Brace & Brace & Timing & Follow-Up & $\begin{array}{l}\text { Definition of } \\
\text { Success Rate }\end{array}$ & Success Rate \\
\hline Price [34] & 1990 & $7 / 16$ & 139 & $25-49$ & Risser 0-2 & Rigid & Charleston brace & Night-time & $>1$ year & $\leq 5^{\circ}$ & $83 \%$ \\
\hline Lee [35] & 2012 & $9 / 16$ & 95 & $25-40$ & Risser 0-2 & Rigid & Charleston brace & Night-time & $\begin{array}{c}>2 \text { years after } \\
\text { skeletal maturity }\end{array}$ & $\leq 5^{\circ}$ & $84.2 \%$ \\
\hline Davis [36] & 2019 & $6 / 16$ & 56 & $25-40$ & Risser 0-2 & Rigid & Providence brace & Night-time & mean 2.21 years & $\leq 5^{\circ}$ & $51.8 \%$ \\
\hline $\begin{array}{c}\text { Ohrt-Nissen } \\
\text { [37] }\end{array}$ & 2016 & $7 / 16$ & 63 & $25-40$ & Risser 0-2 & Rigid & Providence brace & Night-time & 2 years & $\leq 5^{\circ}$ & $57 \%$ \\
\hline Bohl [38] & 2014 & $6 / 16$ & 34 & $25-40$ & Risser 0-2 & Rigid & Providence brace & Night-time & $\begin{array}{c}2 \text { years after } \\
\text { maturity }\end{array}$ & $\leq 5^{\circ}$ or $>45$ degrees & $\begin{aligned} 50 \% & >5^{\circ}, 59 \% \\
& >45^{\circ}\end{aligned}$ \\
\hline Simony [39] & 2019 & $10 / 16$ & 80 & $20-45$ & $\begin{array}{l}\text { Pre or }<1 \text { year } \\
\text { post-menarche }\end{array}$ & Rigid & Providence brace & Night-time & $\begin{array}{l}\text { Till } 1 \text { year after } \\
\text { stop bracing }\end{array}$ & $\leq 5^{\circ}$ & $89 \%$ \\
\hline Coillard [40] & 2007 & $8 / 16$ & 170 & $25-40$ & Risser 0-2 & Soft & SpineCor & Full-time & $\begin{array}{l}2 \text { years after } \\
\text { discontinuing } \\
\text { brace therapy }\end{array}$ & $\leq 5^{\circ}$ & $59.4 \%$ \\
\hline Coillard [41] & 2014 & $16 / 24$ & 32 & $15-30$ & Risser 0-2 & Soft & SpineCor brace & Full-time & 5 years & $\leq 5^{\circ}$ & $73 \%$ \\
\hline
\end{tabular}


Table 6. Ovrview of the comparative studies between braces.e The studies lightened in bold are the ones included in the meta-analysis.

\begin{tabular}{|c|c|c|c|c|c|c|c|c|c|c|c|}
\hline First Author & Year & $\begin{array}{l}\text { Risk of } \\
\text { Bias }\end{array}$ & $\begin{array}{l}\text { Sample } \\
\text { Size }\end{array}$ & Cobb Angle & Skeletal Maturity & $\begin{array}{l}\text { Type of } \\
\text { Brace }\end{array}$ & Brace & Timing & Follow-Up & $\begin{array}{l}\text { Definition of } \\
\text { Success Rate }\end{array}$ & Success Rate \\
\hline Minsk [47] & 2017 & $11 / 24$ & $\begin{array}{l}13 \\
93\end{array}$ & $25-40$ & Risser 0-2 & Rigid & $\begin{array}{c}\text { Rigo- Cheneau } \\
\text { Boston }\end{array}$ & Full-time & $>1$ year & $\begin{array}{l}\leq 5^{\circ} ; \text { no need of } \\
\text { surgery }\end{array}$ & $\begin{array}{c}\text { Spinal surgery: } 0 \% \\
>6^{\circ}: 31 \% \\
\text { Spinal surgery: } \\
34 \%\end{array}$ \\
\hline Hanks [42] & 1988 & $11 / 24$ & $\begin{array}{l}75 \\
25\end{array}$ & $>25$ & Risser 0-4 & Rigid & Wilmington Jacket & $\begin{array}{l}\text { Full-time } \\
\text { Part-time }\end{array}$ & $\begin{array}{l}1 \text { year after } \\
\text { discontinuing } \\
\text { brace }\end{array}$ & $<10^{\circ}$ & $\begin{array}{l}\text { Full-time } 80 \% \\
\qquad 84 \%\end{array}$ \\
\hline Katz [43] & 2010 & $11 / 24$ & $\begin{array}{l}57 \\
43\end{array}$ & $25-40$ & Risser 0-2 & Rigid & Boston brace & $\begin{array}{l}\text { Full-time } \\
\text { Part-time }\end{array}$ & $>1$ year & $\leq 5^{\circ}$ & $\begin{array}{l}82 \%>12 \mathrm{~h} \\
31 \%>7 \mathrm{~h}\end{array}$ \\
\hline Yrjonen [4] & 2006 & $12 / 24$ & $\begin{array}{l}36 \\
36\end{array}$ & $>25^{\circ}$ & Risser sign 0-3 & $\begin{array}{l}\text { Rigid } \\
\text { Rigid } \\
\end{array}$ & $\begin{array}{l}\text { Providence brace } \\
\text { Boston brace }\end{array}$ & $\begin{array}{l}\text { Night-time } \\
\text { Full-time }\end{array}$ & mean 1.8 years & $\leq 5^{\circ}$ & $\begin{array}{l}72 \% \\
78 \% \\
\end{array}$ \\
\hline Janicki [48] & 2007 & $10 / 24$ & $\begin{array}{l}35 \\
48\end{array}$ & $25-40$ & Risser 0-2 & $\begin{array}{l}\text { Rigid } \\
\text { Rigid }\end{array}$ & $\begin{array}{l}\text { Providence brace } \\
\text { Custom TLSO }\end{array}$ & $\begin{array}{l}\text { Night-time } \\
\text { Full-time }\end{array}$ & $>2$ years & $\leq 5^{\circ}$ & $\begin{array}{l}31 \% \\
15 \%\end{array}$ \\
\hline Ohrt-Nissen [49] & 2019 & $13 / 24$ & $\begin{array}{l}40 \\
37\end{array}$ & $25-40$ & Risser 0-2 & $\begin{array}{l}\text { Rigid } \\
\text { Rigid }\end{array}$ & $\begin{array}{l}\text { Providence brace } \\
\text { Boston brace }\end{array}$ & $\begin{array}{l}\text { Night-time } \\
\text { Full-time }\end{array}$ & 2 years & $\begin{array}{c}\leq 5^{\circ} \text { (primary } \\
\text { outcome); curve } \\
\text { progression } \geq 45^{\circ}\end{array}$ & $\begin{array}{l}45 \% \\
38 \%\end{array}$ \\
\hline Weiss [50] & 2005 & $8 / 24$ & $\begin{array}{l}12 \\
10\end{array}$ & $\begin{array}{l}15-30 \text { and }>30 \\
\text { for rigid brace }\end{array}$ & $\begin{array}{l}\text { Risser sign } 0 \text { (one } \\
\text { exeption with } 1 \text { ) } \\
\text { Tanner } 2 \text { or } 3\end{array}$ & $\begin{array}{l}\text { Soft } \\
\text { Rigid }\end{array}$ & $\begin{array}{c}\text { SpineCor } \\
\text { Cheneau brace }\end{array}$ & $\begin{array}{l}\text { Full-time } \\
\text { Full-time }\end{array}$ & mean 3.5 years & $\leq 5^{\circ}$ & $\begin{array}{l}8 \% \\
80 \%\end{array}$ \\
\hline Guo [51] & 2014 & $13 / 24$ & $\begin{array}{l}20 \\
18\end{array}$ & $20-30$ & $\begin{array}{l}\text { Risser } 0-2 \text { Pre or }<1 \\
\text { year post-menarche }\end{array}$ & $\begin{array}{l}\text { Soft } \\
\text { Rigid }\end{array}$ & $\begin{array}{c}\text { SpineCor brace } \\
\text { TLSO }\end{array}$ & $\begin{array}{l}\text { Full-time } \\
\text { Full-time }\end{array}$ & $\begin{array}{l}2 \text { years after } \\
\text { discontinuing } \\
\text { brace therapy }\end{array}$ & $\leq 5^{\circ}$ & $\begin{array}{l}65 \% \\
94 \%\end{array}$ \\
\hline
\end{tabular}




\subsection{Qualitative Analysis}

- Full-time, rigid braces

Thirteen studies described the outcomes of six full-time, rigid braces. Six brace types were individually studied (see Table 4 ).

Weinstein et al. $(n=242)$ included rigid full-time TLSOs (thoraco-lumbo-sacral orthosis) in a study that was designed as RCT to which patient preference cohorts were added (68\% was treated with Boston brace) [6]. This was one of the few studies that defined success as progression to no more than $50^{\circ} \mathrm{Cobb}$ angle and no surgical treatment. Brace treatment was successful in $72 \%$ of cases versus $42 \%$ in the observation only group [6].

The effectiveness of the Boston brace was investigated in three studies [22-24]. The success rate was $51-83 \%$ in a total of 169 patients [22,24]. Yrjönen et al. found that $63 \%$ of boys had a successful treatment compared to $78 \%$ of the girls [23]. The Chêneau brace was investigated in four studies: Pasquini et al. (low quality study) reported a success rate of $81 \%$, Fang et al. of $81 \%$ (defined as no curve progression to $>50^{\circ}$ ) and Pham et al. of $86 \%$ (defined as curve progression $\leq 10^{\circ}$ ) [25-27]. Pham et al. indicated that the Chêneau brace was most effective in the lumbar curves [27]. Zabrowska-Sapeta et al. $(n=79)$, studied the Cheneau brace in combination with physiotherapy. Treatment was successful in $48 \%$ of cases [28]. Maruyama et al. $(n=33)$ investigated the Rigo-Chêneau brace. Success was observed in $76 \%$ of the patients [44]. The progressive action short brace( $(\underline{\mathrm{PASB}})$ was studied by Aulisa et al. in 69 and 163 patients. In this study with low quality $(6 / 16)$, the reported success rate was between 65.6 and $100 \%[29,45]$. Similarly, the Lyon brace was studied by Aulisa et al. in 69 patients and the reported success rate was 99\% [30]. The Gensingen brace was studied by Weiss et al. ( $n=25)$. The percentage of successful treatment was 92\% [31].

The Osaka Medical College Brace was studied by Kuroki et al. $(n=31)$. Treatment was successful in $68 \%$ of the patients [32].

Pressure-adjustable orthosis was developed by Yangmin Lin et al. in $2020(n=24)$. The reported treatment success was 100\% after 1 year of treatment [33].

- $\quad$ Part-time, rigid braces

There were no non-comparative studies.

- $\quad$ Night-time, rigid braces

Eight studies focused on rigid, night-time braces with a total of 762 patients treated with the Charleston or Providence brace. Lauteur et al. $(n=142)$ studied the night-time brace concept. The treatment was successful in $83 \%$ of cases [46].

The Charleston brace was studied by Lee et al. $(n=95)$ and Price et al. $(n=139)$ with a success rate of $83 \%$ and $84 \%$ [34,35]. Price et al. noticed that patients with double curves treated with Charleston brace should be observed closely for the risk of increase in compensatory curves [34].

The Providence brace was studied in four non-comparative studies with low to moderate quality (total $n=56+63+102+34+80)[5,36-39]$. Success rates were between $52 \%$ and $89 \%[36,39]$.

- $\quad$ Full-time soft braces

Two studies by Coillard et al. reported on one type of full-time soft braces (SpineCor), one RCT $(n=68)$ compared to controls (study quality $=16 / 24)$ and one non-comparative cohort $(n=101)$.

With 5 years follow-up or follow-up to more than 2 years after discontinuation, the brace treatment was successful in $59-73 \%$ of the patients [40,41].

- Comparative studies

Minsk et al. $(n=108)$ compared the Rigo-Chêneau brace and a thoraco-lumbo-sacral orthosis (TLSO). Success rate was defined as curve $\leq 5^{\circ}$ and failure defined as need of surgery [47]. No patients with the Rigo-Chêneau needed surgery compared to $34 \%$ of patients with the TLSO brace that needed surgical intervention [47]. 
Two studies compared full-time with part-time braces (part-time was considered: $\leq 16 \mathrm{~h}$-Hanks et al., as prescribed wearing time-or 7-12 h-Katz et al., as actual wearing time) $[42,43]$. Wilmington Jacket (Hanks et al. $n=100$, success rate defined as curve progression $\leq 10^{\circ}$ ) and Boston brace (Katz et al. $n=100$ ) were identified. The Wilmington Jacket full-time group had a success of $80 \%$, while the part-time group had a successful treatment in $84 \%$ of the cases [42]. Boston full-time bracing wear had a success of $82 \%$ and the part-time worn brace of 31\% [43].

Three studies, Yrjönen et al. $(n=72)$, Janicki et al. $(n=83)$, and Ohrt-Nissen et al. $(n=77)$, prospectively compared the Providence brace and the full-time TLSO $[4,48,49]$. Success rate was defined as curve progression $\leq 5^{\circ}$ or residual curve $<45^{\circ}$ [49]. Providence brace was successful in 31\%, when the full-time TLSO was in $15 \%$ [4,48].

Two studies, Weiss et al. $(n=22)$ and Guo et al. (RCT $n=38)$, focused on the SpineCor brace vs TLSO [50,51]. Success was between 8 and $65 \%$ for the SpineCor and between $80 \%$ and the $94.4 \%$ for the TLSO $[50,51]$.

\subsection{Meta-Analysis}

Sixteen studies had medium or low risk-of-bias, with defined success as progression $\leq 5^{\circ}$ and were included in the meta-analysis. The rigid full-time brace had a success of $73.2 \%$ (95\% CI $60.9-85.5 \%$ ), the night-time of 78.7\% (95\% CI 72.4-85\%), and soft braces of $62.4 \%$ (95\% CI 55.1-69.6\%) (see Figure 2). The success rate of observation was only 50\% $(95 \%$, CI $44-56 \%)$ [20,21,41]. In addition, three studies over rigid full-time bracing with medium or low risk-of-bias, when success is defined as progression $\leq 50^{\circ}$, were separately included in the analysis. The success was of $73.2 \%$ (95\% CI, 67.2-79.2\%). The bubble plot shows no relation between the study quality and reported success rates (Figure 3 ).

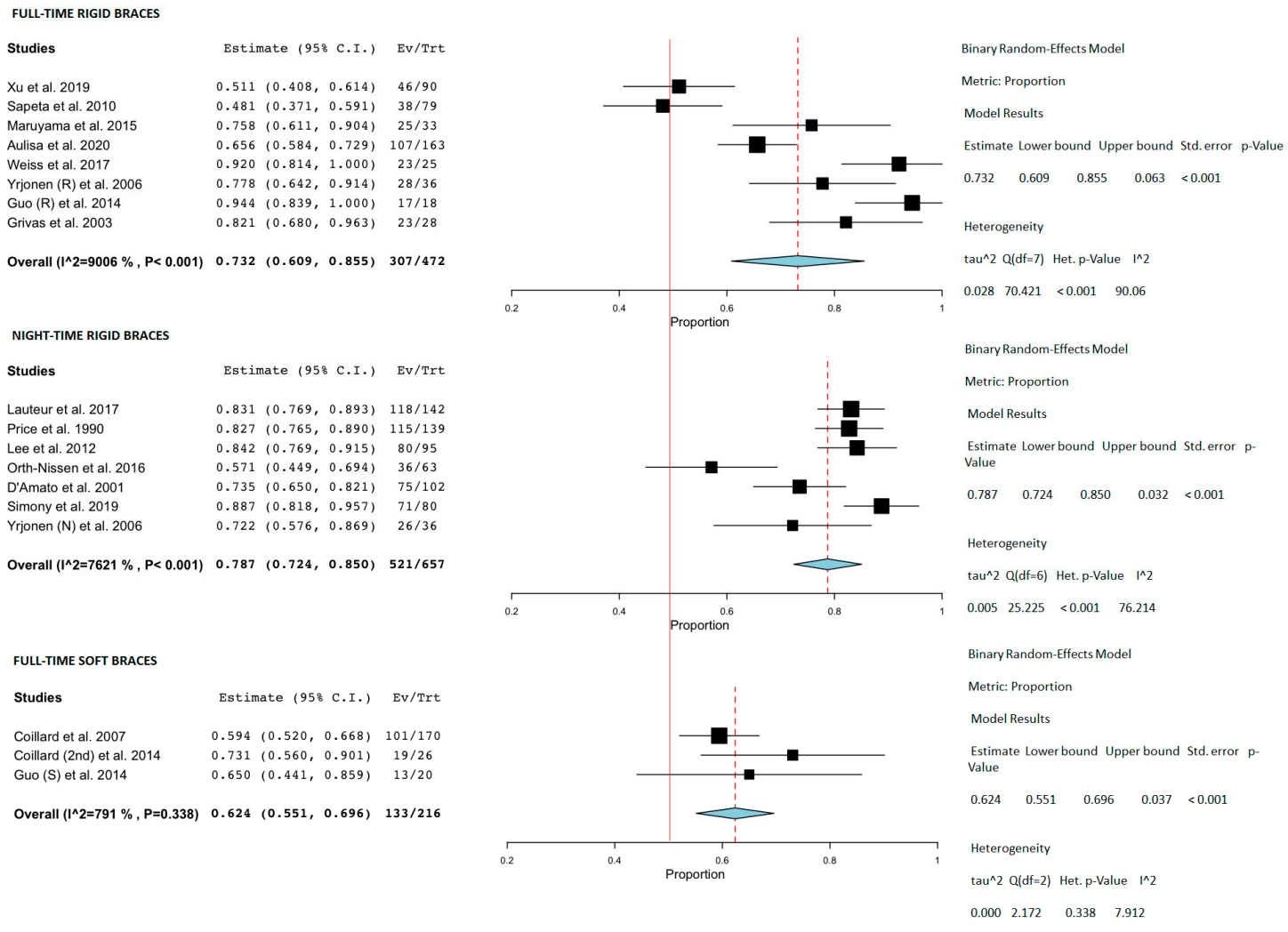

Figure 2. Forest plot of the studies divided per type of concept. Control groups were selected based on type of scoliosis (AIS). A success rate $\left(\leq 5^{\circ}\right)$ and reviews or case reports $(<10 \mathrm{pt}$.) were excluded. The red line represents successes in the case control group (50\%) [4,5,22,24,28,31,34,35,37,39-41,44-46,51]. 


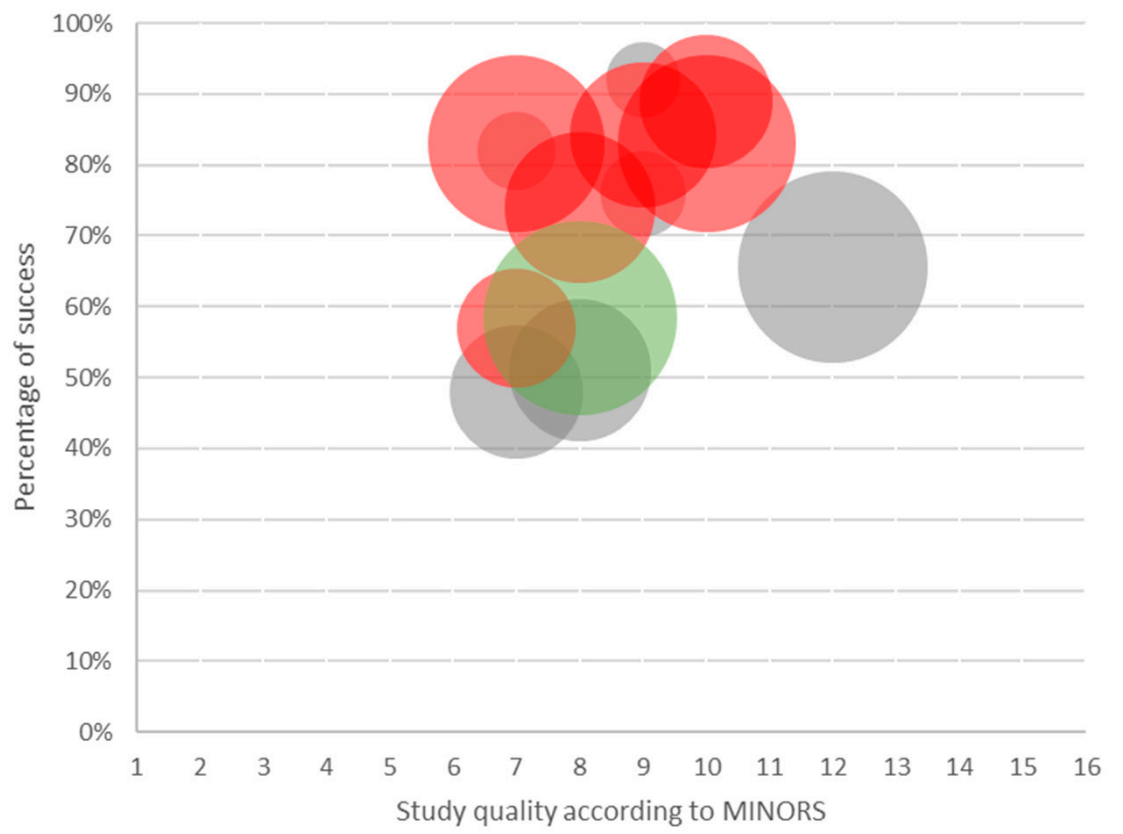

- Xu et al 2019

- Grivas et al. 2003

- Maruyama et al. 2015

- Sapeta et al. 2010

- Weiss et al. 2017

- Aulisa et al. 2020

Lauteur ey al. 2017

- Price et al. 1990

- Lee et al. 2012

- D'Amato et al. 2001

- Nissen et al. 2016

- Simony et al. 2019

Coillard et al. 2007

b

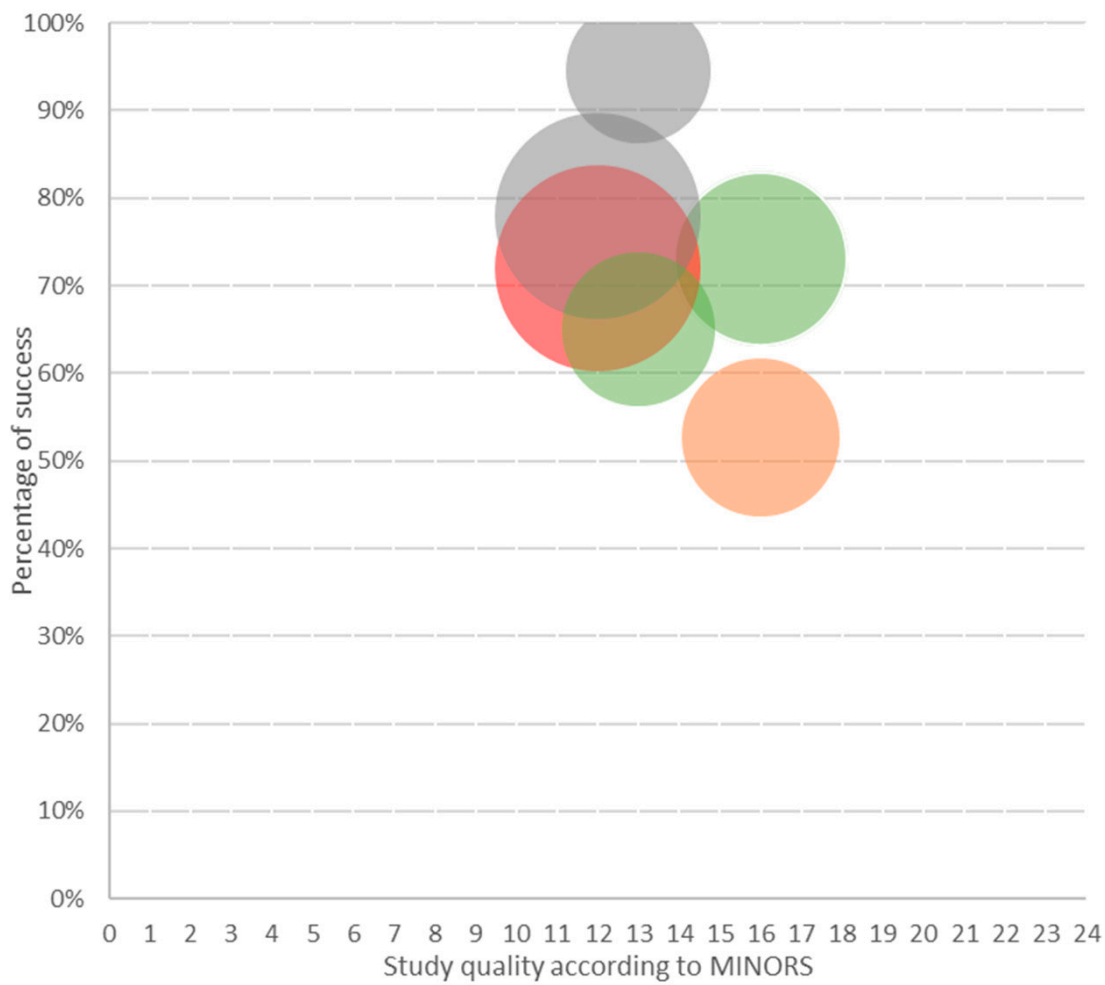

- Coillard et al. 2014

- Coillard et al . 2014 Control group

- Yrjonen et al. 2006 (rigid nighttime brace group) Yrjonen et al. 2006 (rigid full time brace group) - Guo et al. 2014 (rigid full-time brace group) - Guo et al. 2014 (soft full-time brace group)

Figure 3. The bubble graph represents the proportion of the population with less than $5^{\circ}$ Cobb angle progression ( $Y$ axis) relative to the MINORS score ( $\mathrm{X}$ axis) and sample size (diameter of the circle). Thirteen non-comparative studies are represented in (a) and three comparative studies in (b). The grey color represents the rigid full-time concept, the red color the night-time concept, the green one the soft concept, and the orange color represents the control group $[4,5,22,24,28,31,34,35,37,39-41,44-46,51]$. 


\subsection{The Role of Skeletal Maturity}

Fourteen studies were included for the assessment of efficacy in relation to the Risser sign at initiation of brace therapy. Xu et al. divided their study group already based on Risser stage at initiation, so these subgroups were used separately for each category. For the category Risser $0-1$, one paper could be used and the success rate was low, $42 \%$ (95\%CI not applicable because there was only one study). For patients included with Risser 0-2, 10 papers reported a success rate of $71 \%(68-74 \%)$. The $0-3$ category yielded 3 papers with a success rate of $75 \%(70-80 \%)$. The category that included all Risser stages at initiation of therapy showed a little lower success rate of 60\% (54-66\%) (see Figure 4).

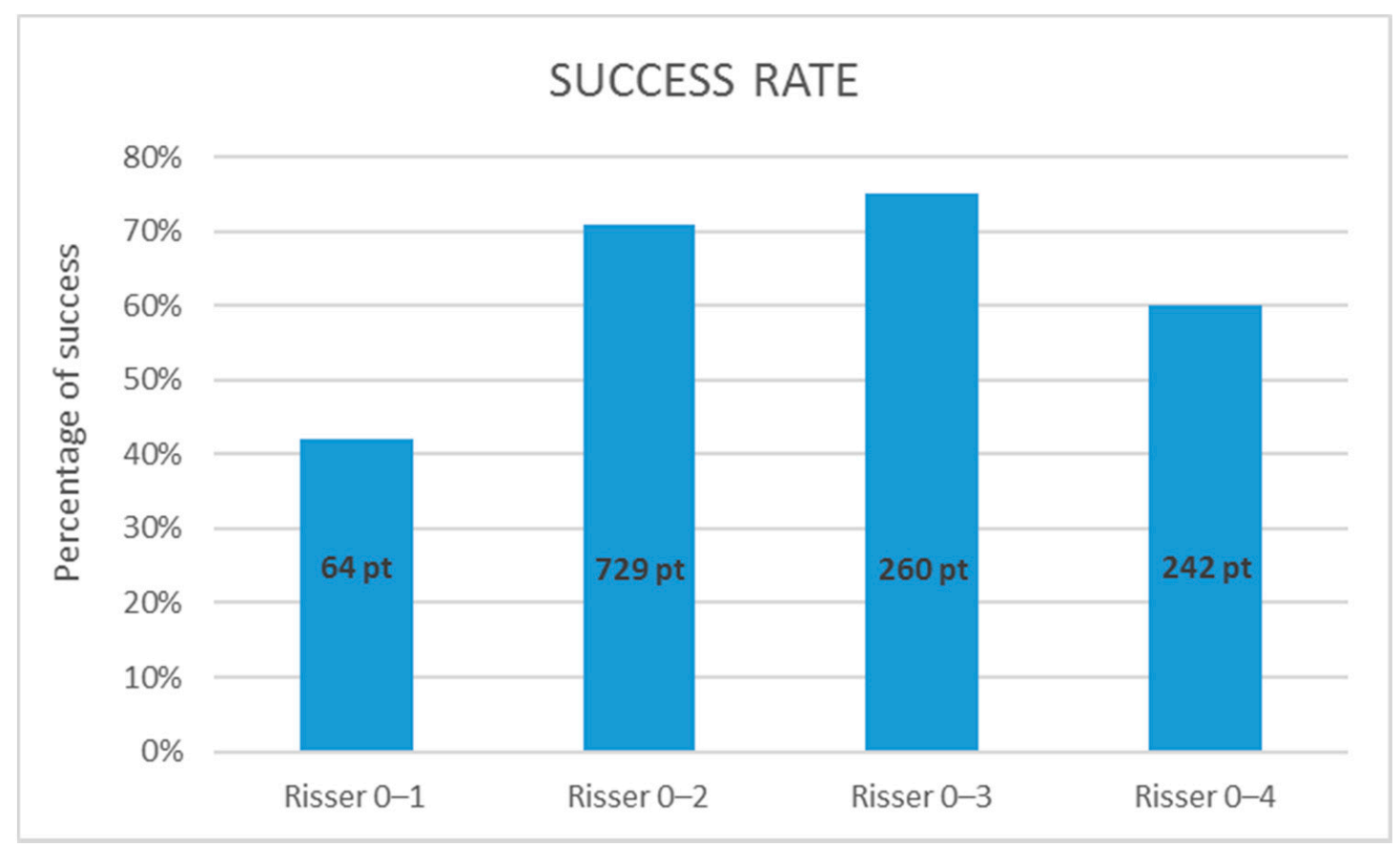

Figure 4. Mean success rate related to maturity. All studies used the Risser sign for assessment of skeletal maturity for initiation of brace treatment and used $\leq 5^{\circ}$ as definition of successful treatment.

\section{Discussion}

This systematic review and meta-analysis aimed to compare the effectiveness of different concepts of bracing for treatment of AIS. Comparison of the effectiveness between the different brace concepts revealed that rigid braces have better outcomes than soft braces and that night-time braces have comparable effectiveness compared to full-time braces. Rigid part-time bracing data were too limited to be included in the meta-analysis $[4,42,48-51]$. Most of the studies used as curve type thoracic, thoraco-lumbar, and lumbar curves with no subgroups organization. Therefore, it was not possible to detect differences in brace efficacy between different curve types. Nevertheless, most of the papers reported curves between $25-40^{\circ}$ Cobb angle (no subgroups) as well as the Risser sign between $0-2$ at initiation of the study and differences between brace types could be analyzed as seen in the results section.

A clear distinction can be made between rigid braces with a constant shape that force the body in a certain position and soft or dynamic orthoses that exert a constant force $[52,53]$. Another distinction is the prescribed wearing time. Full-time is the most used concept, where the patient should wear the brace 18 to $23 \mathrm{~h}$ per day. Part-time bracing is normally prescribed for less than $16 \mathrm{~h}$ per day. Night-time bracing is a different concept that aims to provide better correction because of the reduction of axial loading on the supine spine. [4,39].

Thirty-four studies could be selected for the purpose of this systematic review. Important reasons to exclude studies were: unclear or not stated range of coronal Cobb angle, 
etiology, assessment of maturity at inclusion, type of brace, follow-up time, time in brace, and the success/failure rate. The vast majority of the studies had a moderate to high risk of bias, as also shown by Negrini et al. in their review and SOSORT guidelines $[8,18]$. First, due to the nature of the treatment it is not possible to conduct trials in which patients are blinded. Second, it is difficult to perform RCTs in this kind of treatment because the risk of selection bias [54-56]. In 2008, Bunge et al. tried to perform an RCT study, however with no success since "it is harder to perform a RCT that abolishes or postpones a treatment than a RCT that adds a new treatment" [57]. In 2013, the BRAIST study was published (started as an RCT and ended as an RCT combined with patient preference cohorts). The patient's / parent's preference had led to a substantial proportion of patients refusing randomization and therefore decreasing the external validity. Nevertheless, the efficacy of bracing is generally accepted now because of this trial [6]. In the present study, we included 31 cohort studies and 3 RCTs. In general, estimates of treatment effectiveness are predominantly affected by the quality measures of the study design. In RCTs, for example, if randomization is not adequate, the effects of the treatment are overestimated [58,59]. Interestingly, methodological research has indicated that especially for non-pharmaceutical treatments the validity of observational studies is not necessarily inferior $[60,61]$.

In line with the aim of bracing, success means the avoidance of surgery, as was used in the BRAIST study. However, since criteria for surgery vary between institutes and countries that definition of success is difficult for comparison. The most often used proxy for effectiveness in the available literature is the prevention of progression $\left(\leq 5^{\circ}\right)$. Despite its shortcomings, this outcome can be used for comparisons of different brace concepts and brace types. Ideally, future brace studies should report on (1) the percentage of patients who have $\leq 5^{\circ}$ curve progression per year, at skeletal maturity and two years after ending brace, and the percentage of patients who have $>5^{\circ}$ progression up to skeletal maturity, (2) the percentage of patients with coronal curve angle exceeding $45^{\circ}$ at skeletal maturity, (3) the percentage who have had surgery recommended/undertaken and (4) skeletal maturity parameters [62,63].

Skeletal maturity analysis show that the Risser grade, particularly stages $0-2$, is still the most used classification for skeletal maturity assessment. This should be considered as the parameter for more homogeneous inclusion criteria in future studies. Moreover, our results highlight the correlation between maturity and chance of curve progression.

Furthermore, it is interesting to notice that if rigid full-time braces with success defined as no more than $5^{\circ}$ progression is compared with the data of the same brace concept with definition of success as no more than $50^{\circ}$ of ultimate Cobb angle, the results are comparable. This should need further analyses to understand its relevance since it is hard to objectively compare them.

In our opinion, this systematic review and meta-analysis provides a valuable addition to the existing literature.

To avoid heterogeneity of the data, future studies should also perform stratifications of the subjects related to initial Cobb angle, type of curve, sex, and skeletal maturity.

\section{Conclusions}

Bracing is effective in AIS treatment. Rigid full-time braces, rigid night-time braces, and full-time soft braces are more effective than observation only in terms of halting curve progression. The reported effectiveness of night-time braces is comparable to full-time rigid braces; soft braces perform less well. The Risser sign is still the most used parameter for bone maturity.

Supplementary Materials: The following are available online at https:/ / www.mdpi.com/article/ $10.3390 / \mathrm{jcm} 10102145 / \mathrm{s} 1$, The data presented in this study are available in "Supplementary materials The Effectiveness of Different Concepts of Bracing in Adolescent Idiopathic Scoliosis (AIS) A Systematic Review and Meta-Analysis". 
Author Contributions: Conceptualization, R.M.C., M.C.K., L.C., T.P.C.S.; methodology, L.C., T.P.C.S., J.F.H.; validation, R.M.C., M.C.K., L.C., T.P.C.S.; formal analysis, L.C., H.J.; investigation, L.C., H.J.; resources, L.C., H.J.; data curation, L.C., T.P.C.S.; writing-original draft preparation, L.C.; writingreview and editing, R.M.C., M.C.K., T.P.C.S.; visualization, L.C.; supervision, R.M.C., M.C.K., T.P.C.S. All authors have read and agreed to the published version of the manuscript.

Funding: This research received funding from the EU's H2020 research and innovation program under Marie S. Curie cofound RESCUE grant agreement No 801540.

Institutional Review Board Statement: Not applicable.

Informed Consent Statement: Not applicable.

Data Availability Statement: Data is contained within the article or Supplementary Material. The data presented in this study are available in "Supplementary Materials The Effectiveness of Different Concepts of Bracing in Adolescent Idiopathic Scoliosis (AIS) A Systematic Review and Meta-Analysis".

Conflicts of Interest: The authors declare no conflict of interest. The funders had no role in the design of the study; in the collection, analyses, or interpretation of data; in the writing of the manuscript, or in the decision to publish the results.

\section{References}

1. Konieczny, M.R.; Senyurt, H.; Krauspe, R. Epidemiology of adolescent idiopathic scoliosis. J. Child. Orthop. 2013, 7, 3-9. [CrossRef] [PubMed]

2. Lonstein, J.E. Scoliosis: Surgical versus nonsurgical treatment. Clin. Orthop. Relat. Res. 2006, 87, 248-259. [CrossRef] [PubMed]

3. Weinstein, S.L.; Dolan, L.A.; Cheng, J.C.; Danielsson, A.; Morcuende, J.A. Adolescent idiopathic scoliosis. Lancet 2008, 371, 1527-1537. [CrossRef]

4. Yrjönen, T.; Ylikoski, M.; Schlenzka, D.; Kinnunen, R.; Poussa, M. Effectiveness of the Providence nighttime bracing in adolescent idiopathic scoliosis: A comparative study of 36 female patients. Eur. Spine J. 2006, 15, 1139-1143. [CrossRef] [PubMed]

5. D'Amato, C.R.; Griggs, S.; McCoy, B. Nighttime bracing with the Providence brace in adolescent girls with idiopathic scoliosis. Spine 2001, 26, 2006-2012. [CrossRef]

6. Weinstein, S.L.; Dolan, L.; Wright, J.G.; Dobbs, M.B. Effect of bracing adolescent idiopathic scoliosis. New Engl. J. Med. 2014, 369, 1512-1521. [CrossRef]

7. Lenssinck, M.L.B.; Frijlink, A.C.; Berger, M.Y.; Bierma-Zeinstra, S.M.; Verkerk, K.; Verhagen, A.P. Effect of bracing and other conservative Interventions in the Treatment of Idiopathic Scoliosis in Adolescents: A Systematic Review of clinical trials. Phys. Ther. 2005, 85, 1329-1339. [CrossRef] [PubMed]

8. Negrini, S.; Donzelli, S.; Aulisa, A.G.; Czaprowski, D.; Schreiber, S.; De Mauroy, J.C.; Diers, H.; Grivas, T.B.; Knott, P.; Kotwicki, T.; et al. 2016 SOSORT guidelines: Orthopaedic and rehabilitation treatment of idiopathic scoliosis during growth. Scoliosis Spinal Disord. 2018, 13, 1-48. [CrossRef] [PubMed]

9. Guyatt, G.; Oxman, A.D.; Akl, E.A.; Kunz, R.; Vist, G.; Brozek, J.; Norris, S.; Falck-Ytter, Y.; Glasziou, P.; Debeer, H.; et al. GRADE guidelines: 1. Introduction - GRADE evidence profiles and summary of findings tables. Washington (DC): National Academies P. BMJ 2011, 16, 1-13. [CrossRef]

10. McKee, M.; Britton, A.; Black, N.; McPherson, K.; Sanderson, C.; Bain, C. Methods in health services research: Interpreting the evidence: Choosing between randomised and non-randomised studies. Br. Med. J. 1999, 319, 312-315. [CrossRef] [PubMed]

11. Houwert, R.; Verhofstad, M.; Hietbrink, F.; Kruyt, M. De conventionele RCT voor trauma- en orthopedisch chirurgen: Geen heilige graal. Ned. Tijdschr. Voor Traumachirurgie 2016, 24, 2-5. [CrossRef]

12. Abraham, N.S.; Byrne, C.J.; Young, J.M.; Solomon, M.J. Meta-analysis of well-designed nonrandomized comparative studies of surgical procedures is as good as randomized controlled trials. J. Clin. Epidemiol. 2010, 63, 238-245. [CrossRef] [PubMed]

13. Jacobs, W.C.; Kruyt, M.C.; Verbout, A.J.; Oner, F.C. Spine surgery research: On and beyond current strategies. Spine J. 2012, 12, 706-713. [CrossRef] [PubMed]

14. Jacobs, W.C.; Kruyt, M.C.; Moojen, W.A.; Verbout, A.J.; Öner, F. C No evidence for intervention-dependent influence of methodological features on treatment effect. J. Clin. Epidemiol. 2013, 66, 1347-1355.e3. [CrossRef] [PubMed]

15. Slim, K.; Nini, E.; Forestier, D.; Kwiatkowski, F.; Panis, Y.; Chipponi, J. Methodological index for non-randomized studies (Minors): Development and validation of a new instrument. ANZ J. Surg. 2003, 73, 712-716. [CrossRef]

16. Liberati, A.; Altman, D.; Jennifer, T. The PRISMA Statement for Reporting Systematic Reviews and Meta-Analyses of Studies That Evaluate Health Care Interventions: Explanation and Elaboration. PLoS Med. 2009, 6, 50931. [CrossRef] [PubMed]

17. Ouzzani, M.; Hammady, H.; Fedorowicz, Z.; Elmagarmid, A. Rayyan-a web and mobile app for systematic reviews. Syst. Rev. 2016, 5, 1-10. [CrossRef] [PubMed] 
18. Negrini, S.; Minozzi, S.; Bettany-Saltikov, J.; Chockalingam, N.; Grivas, T.B.; Kotwicki, T.; Maruyama, T.; Romano, M.; Zaina, F. Braces for idiopathic scoliosis in adolescents (Review) summary of findings for the main comparison. Cochrane Database Syst. Rev. 2015. [CrossRef]

19. Wallace, B.C.; Trikalinos, T.A.; Lau, J.; Trow, P.; Schmid, C.H. Closing the Gap between Methodologists and End-Users: R as a Computational Back-End. J. Stat. Softw. 2012, 49, 1-15. [CrossRef]

20. Picault, C.; Demauroy, J.C.; Mouilleseaux, B.; Diana, G. Natural history of idiopathic scoliosis in girls and boys. Spine 1986, 11, 777-778. [CrossRef]

21. Nachemson, A.L.; Peterson, L. E Effectiveness of tretment with a brace in girls who have adolescent idiopathic scoliosis. J. Bone Joint Surg. Am. 1995, 77, 815-822. [CrossRef] [PubMed]

22. Xu, L.; Yang, X.; Wang, Y.; Wu, Z.; Xia, C.; Qiu, Y.; Zhu, Z. Brace Treatment in Adolescent Idiopathic Scoliosis Patients with Curve Between $40^{\circ}$ and $45^{\circ}$ : Effectiveness and Related Factors. World Neurosurg. 2019, 126, e901-e906. [CrossRef]

23. Yrjönen, T.; Ylikoski, M.; Schlenzka, D.; Poussa, M. Results of brace treatment of adolescent idiopathic scoliosis in boys compared with girls: A retrospective study of 102 patients treated with the Boston brace. Eur. Spine J. 2007, 16, 393-397. [CrossRef] [PubMed]

24. Grivas, T.B.; Vasiliadis, E.; Chatziargiropoulos, T.; Polyzois, V.D.; Gatos, K. The effect of a modified Boston brace with anti-rotatory blades on the progression of curves in idiopathic scoliosis: Aetiologic implications. Pediatr. Rehabil. 2003, 6, 237-242. [CrossRef] [PubMed]

25. Pasquini, G.; Cecchi, F.; Bini, C.; Molino-Lova, R.; Vannetti, F.; Castagnoli, C.; Paperini, A.; Boni, R.; Macchi, C.; Crusco, B.; et al. The outcome of a modified version of the Cheneau brace in adolescent idiopathic scoliosis (AIS) based on SRS and SOSORT criteria: A retrospective study. Eur J Phys Rehabil Med 2016, 52, 618-629. [PubMed]

26. Fang, M.-Q.; Wang, C.; Xiang, G.-H.; Lou, C.; Tian, N.-F.; Xu, H.-Z. Long-term effects of the Chêneau brace on coronal and sagittal alignment in adolescent idiopathic scoliosis. J. Neurosurg. Spine 2015, 23, 505-509. [CrossRef]

27. Pham, V.-M.; Herbaux, B.; Schill, A.; Thevenon, A. Evaluation of the Chêneau brace in adolescent idiopathic scoliosis. Évaluation $d u$ résultat $d u$ corset Chêneau dans la scoliose idiopathique l'adolescent 2007, 50, 125-133.

28. Zabrowska-Sapeta, K.; Kowalski, I.M.; Protasiewicz-Fałdowska, H.; Wolska, O. Evaluation of the effectiveness of Chêneau brace treatment for idiopathic scoliosis-Own observations. Pol. Ann. Med. 2010, 17, 44-53. [CrossRef]

29. Aulisa, A.G.; Guzzanti, V.; Galli, M.; Perisano, C.; Falciglia, F.; Maggi, G.; Aulisa, L. Treatment of lumbar curves in adolescent females affected by idiopathic scoliosis with a progressive action short brace (PASB): Assessment of results according to the SRS committee on bracing and nonoperative management standardization criteria. J. Orthop. Traumatol. 2009, 12, S38. [CrossRef]

30. Aulisa, A.G.; Guzzanti, V.; Falciglia, F.; Giordano, M.; Marzetti, E.; Aulisa, L. Lyon bracing in adolescent females with thoracic idiopathic scoliosis: A prospective study based on SRS and SOSORT criteria Orthopedics and biomechanics. BMC Musculoskelet. Disord. 2015, 16. [CrossRef] [PubMed]

31. Weiss, H.-R.; Tournavitis, N.; Seibel, S.; Kleban, A. A Prospective Cohort Study of AIS Patients with $40^{\circ}$ and More Treated with a Gensingen Brace (GBW): Preliminary Results. Open Orthop. J. 2017, 11, 1558-1567. [CrossRef] [PubMed]

32. Kuroki, H.; Inomata, N.; Hamanaka, H.; Higa, K.; Chosa, E.; Tajima, N. Predictive factors of Osaka Medical College (OMC) brace treatment in patients with adolescent idiopathic scoliosis. Scoliosis 2015, 10, 11. [CrossRef] [PubMed]

33. Lin, Y.; Lou, E.; Lam, T.P.; Cheng, J.C.-Y.; Sin, S.W.; Kwok, W.K.; Wong, M.S. The Intelligent Automated Pressure-Adjustable Orthosis for Patients With Adolescent Idiopathic Scoliosis: A Bi-Center Randomized Controlled Trial. Spine 2020, 45, 1395-1402. [CrossRef] [PubMed]

34. Price, C.T.; Scott, D.S.; Reed, F.E.; Riddick, M.F. Nighttime bracing for adolescent idiopathic scoliosis with the Charleston bending brace. Preliminary report. Spine 1990, 15, 1294-1299. [CrossRef]

35. Lee, C.S.; Hwang, C.J.; Kim, D.-J.; Kim, J.H.; Kim, Y.-T.; Lee, M.Y.; Yoon, S.J.; Lee, D.-H. Effectiveness of the Charleston night-time bending brace in the treatment of adolescent idiopathic scoliosis. J. Pediatr. Orthop. 2012, 32, 368-372. [CrossRef] [PubMed]

36. Davis, L.; Murphy, J.S.; Shaw, K.A.; Cash, K.; Devito, D.P.; Schmitz, M.L. Nighttime bracing with the Providence thoracolumbosacral orthosis for treatment of adolescent idiopathic scoliosis: A retrospective consecutive clinical series. Prosthet. Orthot. Int. 2019, 43, 158-162. [CrossRef] [PubMed]

37. Ohrt-Nissen, S.; Hallager, D.W.; Gehrchen, M.; Dahl, B. Flexibility Predicts Curve Progression in Providence Nighttime Bracing of Patients With Adolescent Idiopathic Scoliosis. Spine 2016, 41, 1724-1730. [CrossRef]

38. Bohl, D.D.; Telles, C.J.; Golinvaux, N.S.; Basques, B.A.; DeLuca, P.A.; Grauer, J.N. Effectiveness of Providence nighttime bracing in patients with adolescent idiopathic scoliosis. Orthopedics 2014, 37, e1085-90. [CrossRef]

39. Simony, A.; Beuschau, I.; Quisth, L.; Jespersen, S.M.; Carreon, L.Y.; Andersen, M.O. Providence nighttime bracing is effective in treatment for adolescent idiopathic scoliosis even in curves larger than 35 . Eur. Spine J. 2019, 28, 2020-2024. [CrossRef]

40. Coillard, C.; Vachon, V.; Circo, A.B.; Beauséjour, M.; Rivard, C.H. Effectiveness of the SpineCor brace based on the new standardized criteria proposed by the scoliosis research society for adolescent idiopathic scoliosis. J. Pediatr. Orthop. 2007, 27, 375-379. [CrossRef]

41. Coillard, C.; Circo, A.B.; Rivard, C.H. A prospective randomized controlled trial of the natural history of idiopathic scoliosis versus treatment with the SpineCor brace. Sosort Award 2011 winner. Eur. J. Phys. Rehabil. Med. 2014, 50, 479-487.

42. Hanks, G.A.; Zimmer, B.; Nogi, J. TLSO treatment of idiopathic scoliosis. An analysis of the Wilmington jacket. Spine 1988, 13, 626-629. [CrossRef] 
43. Katz, D.E.; Herring, J.A.; Browne, R.H.; Kelly, D.M.; Birch, J.G. Brace wear control of curve progression in adolescent idiopathic scoliosis. J. Bone Joint Surg. Am. 2010, 92, 1343-1352. [CrossRef] [PubMed]

44. Maruyama, T.; Kobayashi, Y.; Miura, M.; Nakao, Y. Effectiveness of brace treatment for adolescent idiopathic scoliosis. Scoliosis 2015, 10, S12. [CrossRef] [PubMed]

45. Aulisa, A.G.; Giordano, M.; Toniolo, R.M.; Aulisa, L. Long term results after brace treatment with PASB in adolescent idipathic scoliosis. Minerva Anestesiol. 2020. [CrossRef]

46. Lateur, G.; Grobost, P.; Gerbelot, J.; Eid, A.; Griffet, J.; Courvoisier, A. Efficacy of nighttime brace in preventing progression of idiopathic scoliosis of less than $25^{\circ}$. Orthop. Traumatol. Surg. Res. 2017, 103, 275-278. [CrossRef]

47. Minsk, M.K.; Venuti, K.D.; Daumit, G.L.; Sponseller, P.D. Effectiveness of the Rigo Chêneau versus Boston-style orthoses for adolescent idiopathic scoliosis: A retrospective study. Scoliosis Spin. Disord. 2017, 12, 1-6. [CrossRef] [PubMed]

48. Janicki, J.A.; Poe-Kochert, C.; Armstrong, D.G.; Thompson, G.H. A comparison of the thoracolumbosacral orthoses and providence orthosis in the treatment of adolescent idiopathic scoliosis: Results using the new SRS inclusion and assessment criteria for bracing studies. J. Pediatr. Orthop. 2007, 27, 369-374. [CrossRef]

49. Ohrt-Nissen, S.; Lastikka, M.; Andersen, T.B.; Helenius, I.; Gehrchen, M. Conservative treatment of main thoracic adolescent idiopathic scoliosis: Full-time or nighttime bracing? J. Orthop. Surg. 2019, 27, 1-8. [CrossRef]

50. Weiss, H.-R.; Weiss, G.M. Brace treatment during pubertal growth spurt in girls with idiopathic scoliosis (IS): A prospective trial comparing two different concepts. Pediatr. Rehabil. 2005, 8, 199-206. [CrossRef]

51. Guo, J.; Lam, T.P.; Wong, M.S.; Ng, B.K.W.; Lee, K.M.; Liu, K.L.; Hung, L.H.; Lau, A.H.Y.; Sin, S.W.; Kwok, W.K.; et al. A prospective randomized controlled study on the treatment outcome of SpineCor brace versus rigid brace for adolescent idiopathic scoliosis with follow-up according to the SRS standardized criteria. Eur. Spine J. 2014, 23, 2650-2657. [CrossRef]

52. Emans, M.J.B.; Hresko, M.D.M.T.; Hall, M.D.J.E.; Hedequist, C.D.; Karlin, M.D.L.; Miller, M.D.J.; Miller, R.R.; Magin, C.P.O.M.; McCarthy, R.N.C.; Cassella, R.M.; et al. Reference Manual for the Boston Scoliosis Brace; 2003; Available online: https://www. bostonoandp.com/Customer-Content/www/CMS/files/BostonBraceManual.pdf (accessed on 12 January 2021).

53. Fayssoux, R.S.; Cho, R.H.; Herman, M.J. A history of bracing for idiopathic scoliosis in north America. Clin. Orthop. Relat. Res. 2010, 468, 654-664. [CrossRef]

54. Donzelli, S.; Zaina, F.; Minnella, S.; Lusini, M.; Negrini, S. Consistent and regular daily wearing improve bracing results: A case-control study. Scoliosis spinal Disord. 2018, 13, 16. [CrossRef]

55. Misteroska, E.; Glowacki, J.; Głowacki, M.; Okręt, A. Long-term effects of conservative treatment of Milwaukee brace on body image and mental health of patients with idiopathic scoliosis. PLoS ONE 2018, 13. [CrossRef]

56. Aulisa, A.G.; Guzzanti, V.; Falciglia, F.; Galli, M.; Pizzeti, P.; Aulisa, L. Curve progression after long-term brace treatment in adolescent idiopathic scoliosis: Comparative results between over and under 30 Cobb degrees—SOSORT 2017 award winner. Scoliosis Spin. Disord. 2017, 12. [CrossRef]

57. Bunge, E.M.; De Koning, H.J. Bracing patients with idiopathic scoliosis: Design of the Dutch randomized controlled treatment trial. BMC Musculoskelet. Disord. 2008, 9, 1-7. [CrossRef] [PubMed]

58. Kunz, R.; Oxman, A.D. The unpredictability paradox: Review of empirical comparisons of randomised and non-randomised clinical trials. BMJ 1998, 317, 1185-1190. [CrossRef] [PubMed]

59. Vandenbroucke, J.P. Why do the results of randomised and observational studies differ? Statistical theory conflicts with empirical findings in several areas of research. BMJ 2011, 343, 1128. [CrossRef]

60. Ioannidis, J.P.; Lau, J. Completeness of Safety Reporting in Randomized Trials. JAMA 2001, 285, 437. [CrossRef] [PubMed]

61. Concato, J. Randomized controlled trial, observational studies and the hierarchy of research designs. Int. J. Biol. Markers 2000, 15, 79-83. [CrossRef] [PubMed]

62. Richards, B.S.; Bernstein, R.M.; D'Amato, C.R.; Thompson, G.H. Standardization of criteria for adolescent idiopathic scoliosis brace studies: SRS Committee on Bracing and Nonoperative Management. Spine 2005, 30, 2068-2075. [CrossRef] [PubMed]

63. Upadhyay, S.S.; Nelson, I.W.; Ho, E.K.; Hsu, L.C.; Leong, J.C. New Prognostic Factors to Predict the Final Outcome of Brace Treatment in Adolescent Idiopathic Scoliosis. Spine 1995. [CrossRef] [PubMed] 